\title{
Vagus Nerve Injury During Carotid Endarterectomy: A Cadaveric Study
}

\author{
Karotis Endarterektomi Sırasında Oluşan Vagus Siniri Yaralanması: \\ Kadavra Çalışması
}

\author{
Musa Çırak $^{1} \oplus$, Baran Bozkurt² $\oplus$, Kaan Yağmurlü ${ }^{3 \oplus}$ \\ ${ }^{1}$ Bakirkoy Dr. Sadi Konuk Training and Research Hospital, University of Health Sciences, Department of Neurosurgery, Istanbul, Turkey \\ ${ }^{2}$ Maslak Acıbadem Hospital, Department of Neurosurgery, Istanbul, Turkey \\ ${ }^{3}$ Department of Neurological Surgery University of Virginia Health System, Charlottesville, Virginia, USA
}

Received: 11 February 2020 / Accepted: 25 February 2020 / Publication date: 26 March 2020

Cite as: Cirak M, Bozkurt B, Yagmurlu K. Vagus nerve injury during carotid endarterectomy: A cadaveric study. Med J Bakirkoy 2020;16(1):33-9.

\section{ABSTRACT}

Objective: Vagus nerve injury is one of the most feared and highly prevalent complications of carotid endarterectomy (CEA). The aim of this study is to demonstrate the bilateral positional variations of the common carotid artery (CCA), vagus nerve and internal jugular vein (IJV) inside the carotid sheath in postmortem cadaveric specimens.

Method: Carotid endarterectomy procedure was performed bilaterally step by step in 20 cadavers and every step was photographed. Positional variations of vagus nerve, CCA and IJV inside right and left carotid sheaths were evaluated.

Results: In all dissections anatomical relations between vagus nerve and vascular structures were identified. The right vagus nerve was positioned posteriorly, medially, and anteriorly to IJV and CCA in 8 (40\%), 4 (20\%) and 4 (20\%) of the specimens, respectively. In $2(10 \%)$ specimens right vagus nerve was posterior to the IJV and in 2 (10) specimens' right vagus nerve was positioned posterior to the CCA. The left vagus nerve was positioned anteriorly, centrally, and posteriorly to IJV and common carotid artery in 10 (50\%), 2 (10\%) and 5 (25\%) of the specimens, respectively. In 2 (10\%) specimens left vagus nerve was positioned posterior to IJV. In 1 (5\%) specimen the vagus nerve was located posterior to CCA.

Conclusion: In right and left anatomical relations between vagus nerve and vascular structures, considerable asymmetry was seen in anterior and middle positioning of vagus nerve. During CEA, taking this asymmetry into consideration is important to prevent possible cranial nerve injury complications.

Keywords: anatomy, vagus nerve, carotid artery, endarterectomy, cadaveric study

Öz

Amaç: Vagus sinir hasarı, karotis endarterektominin (CEA) en çok korkulan ve yüksek prevalans gösteren komplikasyonlarından biridir. Bu çalışmanın amacı postmortem kadavra örneklerinde karotid kılıfın içindeki common karotid arter (CCA), vagus siniri ve internal juguler ven (IJV)'nin pozisyonel varyasyonlarını göstermektir.

Yöntem: Karotis endarterektomi işlemi 20 kadavrada bilateral olarak (40) adım adım yapıldı ve her adım fotoğraflandı. Vagus Sinirinin sağ ve sol karotis kılıflarının içinde CCA ve IJV arasındaki pozisyonel varyasyonları değerlendirildi.

Bulgular: Tüm diseksiyonlarda vagus siniri ve vasküler yapılar arasındaki anatomik ilişkiler belirlendi. Sağ vagus siniri, örneklerin 8 (\%40), 4 (\%20) ve 4 (\%20)'ünde sırasıyla IJV ve CCA'ya göre posterior, medial ve anterior yerleşimliydi. iki (n=2/10) örnekte sağ vagus siniri IJV'ye posterior yerleşimli olup, 2 (\%10) örnekte sağ vagus siniri CKA göre posterior yerleşimliydi. Sol vagus siniri, örneklerin 10 (\%50), 2 (\%10) ve 5 (\%25)'inde sirasıly IJV ve CKA'e göre anterior, medial ve posterior olarak yerleşimliydi. Spesimenlerin ikisinde $(n=2 / \% 10)$ sol vagus siniri IJV'ye göre posterior yerleşimliydi. Bir örnekte ise ( $n=1 / \% 5)$ vagus siniri CCA'in posteriorunda yerleşikti. Sonuç: Vagus siniri ve vasküler yapılar arasındaki sağ ve sol anatomik ilişkilerde vagus sinirin ön ve orta konumlandırılmasında belirgin asimetri görüldü. Bu asimetriye CEA sırasında dikkat edilmesi, olası sinir yaralanmaları komplikasyonlarını önlemek için önemlidir.

Anahtar kelimeler: anatomi, vagus siniri, karotis arter, endarterektomi, kadavra çalıșması

Corresponding Author:

musacirak@hotmail.com
M. Çırak 0000-0002-0175-9655

B. Bozkurt 0000-0001-5824-3249 K. Yağmurlu 0000-0002-7635-2809

(C) Telif hakkı Sağlık Bilimleri Üniversitesi Bakırköy Dr. Sadi Konuk Eğitim ve Araştırma Hastanesi'ne aittir. Logos Tıp Yayıncılık tarafindan yayınlanmaktadır. Bu dergide yayınlanan bütün makaleler Creative Commons Atff-GayriTicari 4.0 Uluslararası Lisansı ile lisanslanmıştır.

(C) Copyright Health Sciences University Bakırköy Sadi Konuk Training and Research Hospital. This journal published by Logos Medical Publishing. Licenced by Creative Commons Attribution-NonCommercial 4.0 International (CC BY-NC 4.0) 


\section{INTRODUCTION}

Stenosis caused by atherosclerotic plaques in common carotid artery (CCA) and internal carotid artery (ICA) are common findings as is the case for other vascular structures. Carotid artery stenosis are responsible for $20-25 \%$ of all ischemic strokes ${ }^{(1)}$. Although risk increases when the level of stenosis exceeds $70 \%$, some asymptomatic stenosis may need intervention if there are accompanying factors. Carotid endarterectomy (CEA) and carotid artery stenting (CAS) are recommended in patients with symptomatic $\geq 50 \%$ stenosis or asymptomatic $\geq 70 \%$ stenosis ${ }^{(1)}$. Carotid endarterectomy is a conventional surgical technique to prevent stroke and is performed by vascular surgeons, cardiovascular surgeons and neurosurgeons.(2) Given the stroke prevalence and the accompanying disability caused by it, the CEA technique has become very important. Although CAS was considered an alternative when it was first performed in 1994, it still hasn't become the gold standard in stroke prevention. One of the major complications of the CEA technique is the cranial nerve injury ${ }^{(1,3)}$. Cranial nerve injury following CEA varies from $5 \%$ to $50 \%$ and vagus nerve injury following CEA reported between $1.5 \%$ and $35 \%$ (4). Especially vagus nerve and its branches (the laryngeals), and hypoglossal nerve injuries may cause debilitating clinical syndromes.

Better understanding of the anatomy of vagus nerve and related structures is crucial to minimize the risk of injury during CEA. The relation of the nerves to the carotid artery and their common variations should be also known. In this study, we have shown step by step neuroanatomy of the CEA procedure, as well as the bilateral positional variations of the CCA, vagus nerve and internal jugular vein (IJV) inside the carotid sheath in postmortem cadaveric specimens. Furthermore, CEA and endovascular treatment methods are compared considering the recent studies in the literature.

\section{MATERIAL and METHODS}

CEA procedure was performed step by step on 20 formalin-fixed adult cadaveric specimens (40 sides). The specimens after routine procedures were fixed in $10 \%$ formaldehyde solution and photographs were taken of representative cases. Cadaveric dissections were performed by K.Y at the Skullbase lab, Barrow Neurological Institute. Dissections were made under the operating microscope (Carl Zeiss surgical Microscope Meditec AG, Oberkochen, Germany) with $x 6$ and $x 40$ magnifications. Conventional microneurosurgical instruments were used for dissections. Positional variations of vagus nerve, carotid artery and IJV inside right and left carotid sheaths were revealed.

\section{Surgical Technique}

Patient was laid in supine position with the head turned 45 degrees contralateral to the surgical intervention site. Incision was done $2-3 \mathrm{~cm}$ above the clavicle anteriorly along the sternocleidomastoid muscle (SCM), superiorly until $1.5-2 \mathrm{~cm}$ to the mastoid tip and posteriorly below $1 \mathrm{~cm}$ of the mandibular angle. After the skin was incised, the platysma was split parallel to the skin incision. Anterior edge of the SCM and superior edge of the omohyoid muscle were identified at this point. The tip of the angle formed by the SCM and omohyoid muscle was directed toward the carotid artery. Trachea was retracted medially and SCM laterally. Surrounding tissues were dissected after the bifurcation was identified. The carotid bifurcation was exposed between $2 \mathrm{~cm}$ caudal to the bifurcation and cranially to the lower border of the digastric muscle. After dissections were completed vagus nerve, CCA and IJV were identified and CEA was performed (Figures 2 and 3 ). Possible positions of the vagal nerve relative to CCA and IJV are shown in a scheme (Figure 1). The positions and localisation of vagus nerve was defined as follows;

- Anteriorly between ICA and IJV

- Centrally between ICA and IJV

- Posteriorly between ICA and IJV

- Posterior to ICA

- Posterior to IJV

\section{RESULTS}

The relations of vagus nerve in both sides are summarized in Figure 1 and Table 1. In all dissections anatomical relations between vagus nerve and vascular structures could be identified. In $8(40 \%)$ specimens the right vagus nerve was positioned posteriorly to IJV and CCA. In 4 (20\%) specimens' right vagus 


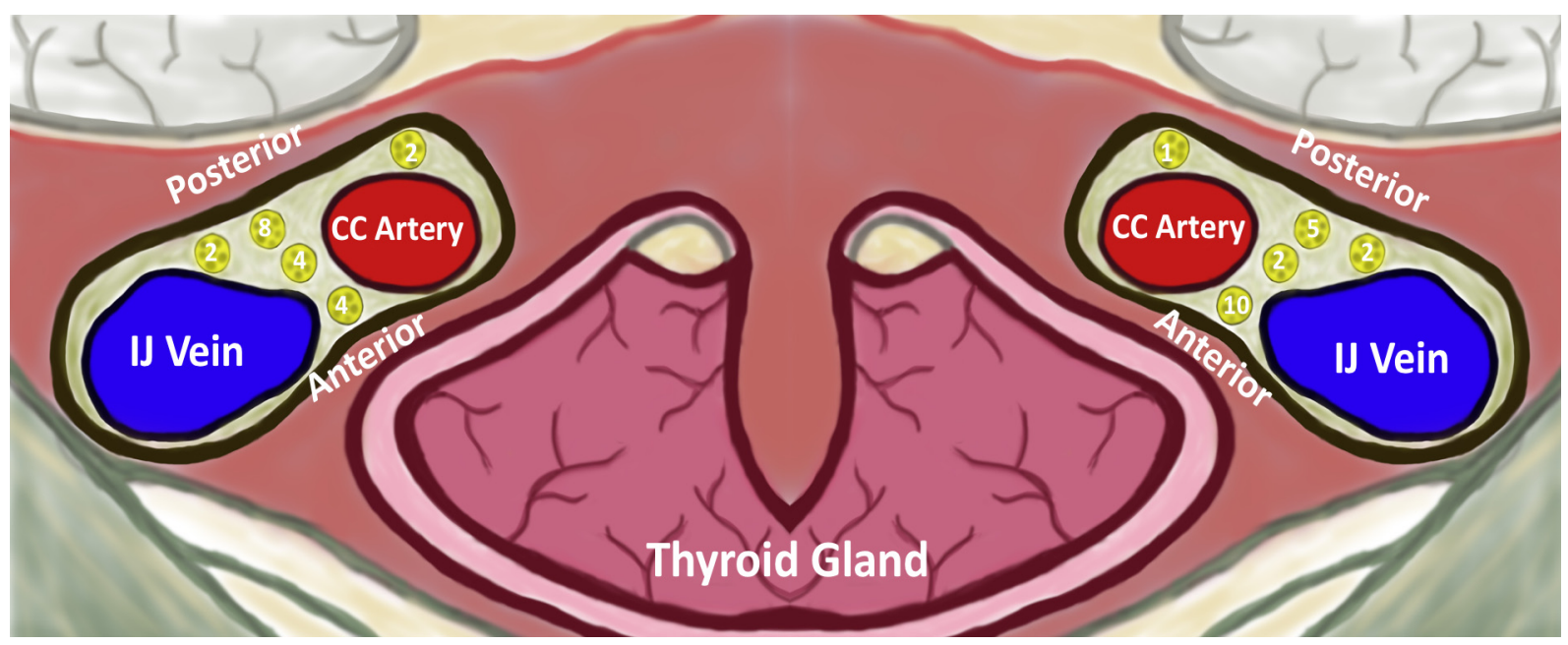

Figure 1. Schematic description of anatomical relations between vagus nerve (labelled with yellow points), common carotid artery and internal jugular vein.

Table 1. Anatomical relations between vagus nerve, common carotid artery and internal jugular vein.

\begin{tabular}{|c|c|c|c|c|c|}
\hline \multirow[b]{2}{*}{ Vagus Nerve } & \multicolumn{3}{|c|}{ Between IJV and CCA } & \multirow[b]{2}{*}{ Posterior to IJV } & \multirow[b]{2}{*}{ Posterior to CCA } \\
\hline & Anterior & Middle & Posterior & & \\
\hline Left vagus nerve & $10(50 \%)$ & 2 (10\%) & $5(25 \%)$ & $2(10 \%)$ & $1(5 \%)$ \\
\hline Right vagus nerve & $4(20 \%)$ & $4(20 \%)$ & $8(40 \%)$ & $2(10 \%)$ & $2(10 \%)$ \\
\hline
\end{tabular}

CCA: common carotid artery, IJV:Internal jugular vein

nerve was positioned in the middle of the IJV and common carotid artery. In $4(20 \%)$ specimens right vagus nerve was positioned anterior to IJV and CCA. In $2(10 \%)$ specimens right vagus nerve was posterior to the IJV and in $2(10 \%)$ specimens right vagus nerve was positioned posterior to the CCA.

The left vagus nerve was located anterior to IJV and common carotid artery in $10(50 \%)$ specimens. The left vagus nerve was positioned in the middle of the IJV and common carotid artery in $2(10 \%)$ specimens. In $5(25 \%)$ specimens left vagus nerve positioned posterior to IJV and CCA. In 2 (10\%) specimens left vagus nerve positioned posterior to IJV. In 1 (5\%) specimen the vagus nerve was positioned posterior to CCA. In right and left side, a considerable asymmetry was seen in anterior and middle positioning of vagus nerve. and vascular structures.

\section{DISCUSSION}

Our study demonstrated that there was a considerable asymmetry between vagus nerve, CCA and IJV both at right and left sides. Carotid endarterectomy is a well-established safe procedure for treatment of carotid artery stenosis ${ }^{(5)}$. With CEA the risk of stroke and mortality could be avoided. Although CEA is regarded as a safe procedure, reported complications include cardiac and hemodynamic complications (myocardial infarction etc), central neurological complications (ischemic attack, intracerebral hemorrhage etc.) and cranial nerve injuries at surgical site. $(1,5)$. The injuries of cranial nerves related with CEA may be seen in hypoglossal nerve, facial nerve, vagus nerve and its branches and rarely in glosspharyngeal nerve ${ }^{(2,4,5)}$. The reported incidence of cranial nerve injury following CEA may be up to $\% 50$ which was reported differently across studies ${ }^{(4,5)}$. The most common cranial nerve injury following CEA was reported to involve hypoglossal nerve and the second is variably reported in the literature as facial nerve or vagus nerve ${ }^{(2-4)}$. Delicate dissection and prompt knowledge of cranial nerve tracts, their relations with surrounding structures and anatomical variations are the fundamental steps for preventing cranial nerve injury during CEA. 


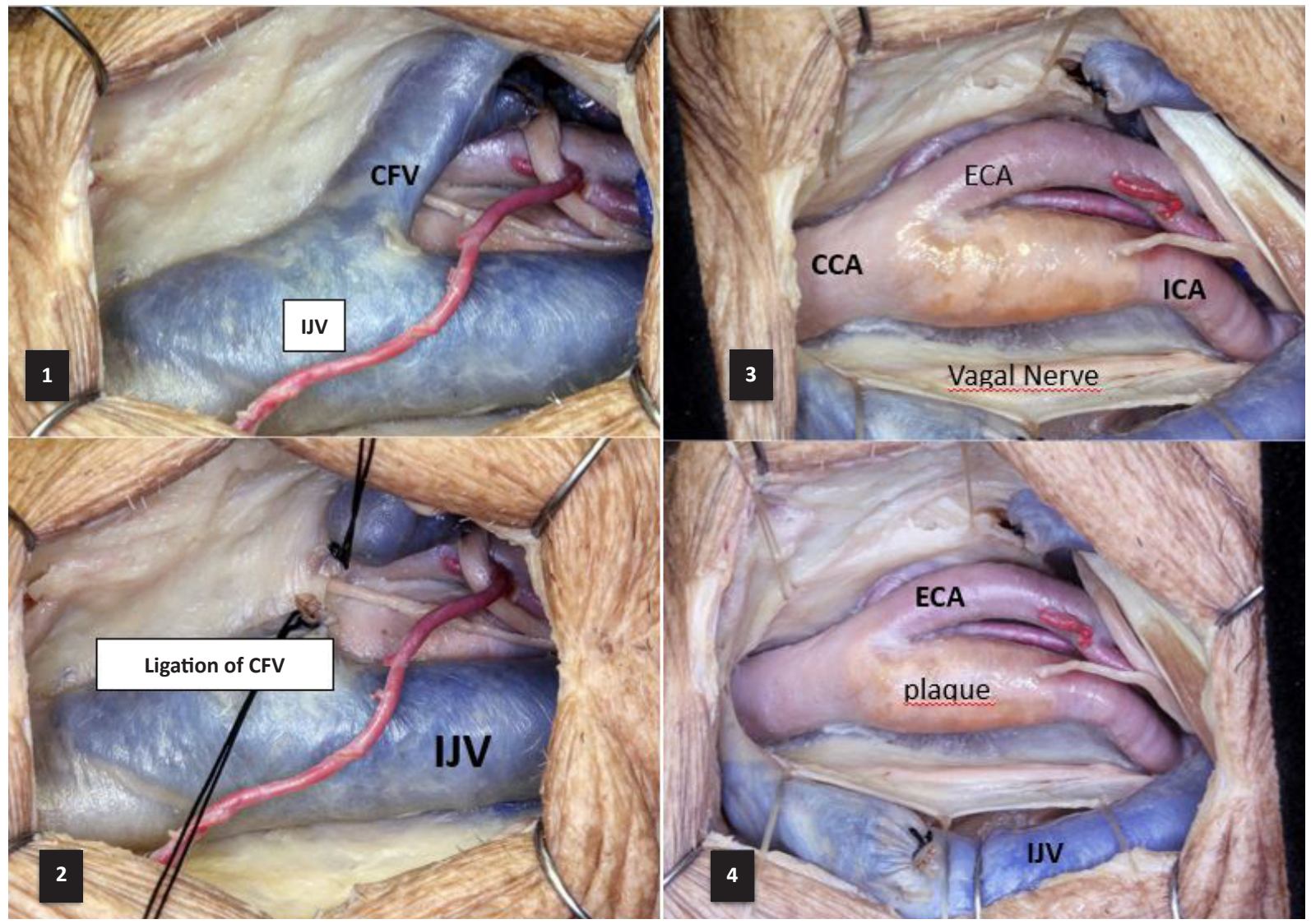

Figure 2. The dissection steps of carotid endarterectomy (continues in Figure 3).

2.1. The first encountering vessel is the internal jugular vein and branch of superior thyroid artery. This vein is located lateral to the internal carotid artery. C the common facial vein (CFV), hypoglossal nerve and its descending branch that can be sacrified.

2.2. We see the ligation of the common facial vein. The carotid artery comes into view.

2.3. After ligation of facial vein, bifurcation of common carotid artery (CCA), atheromatous plaque of internal carotid artery (ICA), External carotid artery (ECA), hypoglossal nerve, vagal nerve come into view

2.4. Closer view of the same anatomic structure seen in Figure 1.3

During the CEA, vagus nerve injury is one of the most feared and highly prevalent complication that was reported up to $35 \%$ of the cases ${ }^{(2,4)}$. Unilateral damage to vagus nerve or recurrent laryngeal nerve can be asymptomatic, however if bilateral carotid reconstruction is planned the risks become more prevalent. Direct injury to the vagus nerve or indirect injury to the recurrent laryngeal branch of the vagus nerve due to direct or retraction can cause hoarseness and loss of cough mechanism due to paralysis of the ipsilateral vocal cord. Bilateral injuries can lead to airway congestion and can be life-threatening ${ }^{(4)}$. Therefore, in a surgical procedure, it is very important to know the relation of the vagus nerve with its surroundings and its positional anatomy inside the carotid sheath. Numerous studies have been done reporting the variational anatomy of the cervical vagus nerve ${ }^{(6-9)}$.
Usually vagus nerve lies between IJV and CCA inside the carotid sheath ${ }^{(3,10)}$. However vagus can be seen in anterolateral, and posterolateral to the CCA or medial to IJV. In an anatomical study Lo et al. dissected 36 cadavers to detect the course of vagus and hypoglossal nerve in 67 carotid specimens ${ }^{(11)}$. In itsmost common form, the vagus nerve was located posterior to the carotid bifurcation in $60 \%$ of the subjects. Vagus nerve was also reportedly located at posterolateral $(36 \%)$, posteromedial $(3 \%)$, and anterolateral to carotid bifurcation (1.5\%). The relation between vagus nerve and CCA was found to be asymmetrical in 17 out of the 31 cadavers without predominance to either side ${ }^{(11)}$. In our study, it has been shown that the position of the vagus nerve showed asymmetry inside the carotid sheath on each side. We have shown that right vagus was anteriorly posi- 


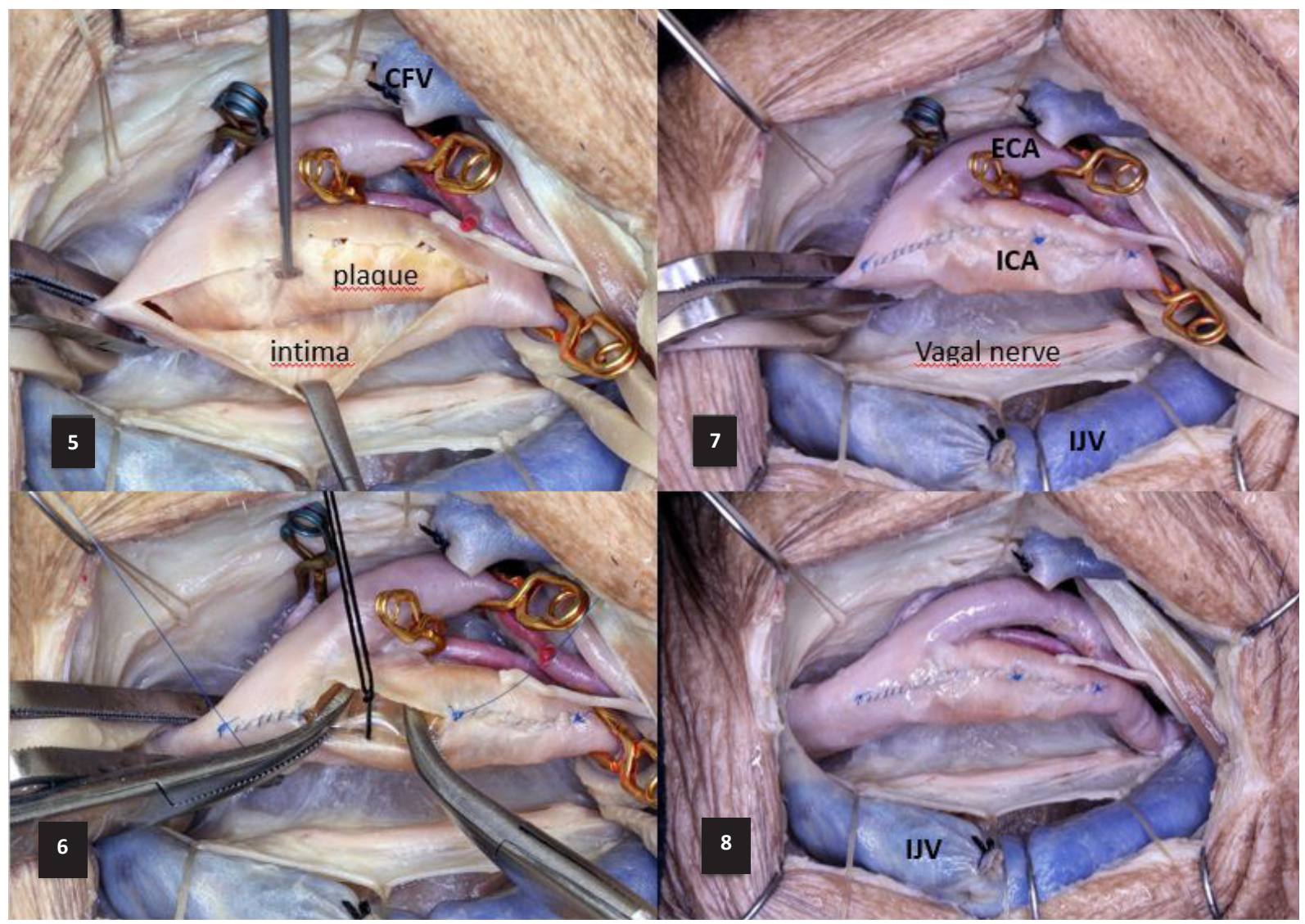

Figure 3. The dissection steps of carotid endarterectomy.

3.5. Procedure of CEA; Clipping order; ICA, CCA, ECA; Dissection of plaque from intima of ICA

3.6. Closing Stage: After the dissection of plaque, CCA and ICA are closed with 6/0 prolene sutures.

3.7. Closing stage is completed but still clipping

3.8. All Clips removed removed. Removing order: ECA , CCA, ICA

tioned closer to midline when compared with the left side and its posterior position.

The consensus on the anatomical position of the vagus nerve inside the carotid sheath is its being in-between the CCA and IJV ${ }^{(10)}$. In this study we have shown the positional variance of the vagus nerve in axial plane as anterior middle and posterior position in between the CCA and IJV and posterior to CCA or IJV. In our anatomical findings, it was observed that the left side vagus nerve was mostly localized anterior to the carotid sheath, and the right side vagus nerve was located behind the sheath. Therefore, considering these findings, it can be interpreted that a risk of direct injury to the vagus nerve or indirect injury to the recurrent laryngeal nerve is greater during a CEA procedure performed on the left side. Therefore anatomical variations should be kept in mind while planning a procedure on this side. Classical CEA approach to the right side can be considered safer for the right side. A more lateral approach such as a retrojugular approach can be considered instead of a classical antejugular approach for a left sided procedures depending on these findings ${ }^{(12)}$. On the other hand, since the sample size is low in our study, further studies on the variations of the vagus nerve are required to show the least risky approach method for the CEA procedure. Recurrent laryngeal nerve (RLN) rooted from the vagus nerve is also at risk during CEA. Direct trauma to the RLN is unusual however, if a trauma (sharp, blunt, thermal, etc.) to the vagus nerve occurs; fibers inside the vagus nerve could be damaged. A non-recurrent laryngeal nerve which occasionally arises from the vagus nerve near the carotid bifurcation should be also kept in the mind $(6 \%)^{(4,9,12)}$. 
In carotid endarterectomy staples had always been used in the treatment for carotid stenosis. However, since the treatment modalities of carotid balloon angioplasty and stenting have been developed the debate aboult the superior treatment has arisen. There has been a number of randomized trials as well as ongoing ones to answer the question of "Will carotid stenting take the place of carotid endarterectomy?" However, the studies have been the source of more debate. It should be more appropriate at this point to suggest that studies exploring the question of the treatment method are better suited for each patient individually, rather than an end-all treatment for the carotid stenosis entity ${ }^{(13,14)}$.

If the patient is symptomatic or asymtomatic, indications and treatment remain controversial. Despite that debate, CEA is still accepted to be the most efficient intervention to decrease the risk of stroke due to carotid artery stenosis ${ }^{(14,15)}$.

The carotid endarterectomy is a surgical modality with the inherent risk of general anesthesia and progressive increase in operative risk on recurrent operations due to simple postoperative fibrosis. The carotid balloon angioplasty and stenting on the other hand is an operation done with local anesthesia, which inherently be better suited for patients with multiple comorbidities ${ }^{(14,16)}$. By deconstructing the two modalities down to its basics lets us see how the patient groups for the two treatments differ. Despite group randomization may be well done in a study, we could tell from certain factors which treatment protocol could be better for a specific patient. Therefore, the inclusion criteria for the studies must be well adjusted to account for the patient group that fall in the grey area between these boundaries $(17,18)$.

It should also be kept in mind that both modalities are surgical treatment methods. In other words, the surgical expertise plays a major role in the outcome rates of both treatment methods. This phenomenon leads to a lower reproducibility in the treatment methods. The variations in the outcome rates regardless of the treatment method could lead to one option better in a one well organized randomized trial and another in the next $(16,17,19)$.
Another important point about this treatment methods is that debate involves the asymptomatic patient group despite the level of stenosis ${ }^{(20)}$. It is important to work on the indications for each treatment depending on both the stenosis level and whether if the patient is symptomatic or not. Despite the treatment method, justifying the risk for the operation must be the principal issue. Risk- benefit assessment should be carefully done in all situations regardless of the study which brings a whole new set of variables in the design of the randomized studies. Stenting is comparably a new treatment and is highly defendant on the quality of the materials used as well ${ }^{(17,19)}$. The ongoing advances in the material engineering may prove that although stenting is doubtful in the long run, the carotid endarterectomy may not be in the same point versus stenting in the near future.

There are various mechanism of vagal nerve injury during CEA. Usually it is caused by direct trauma to the vagal nerve by retraction, stretch, dissection, excessive manipulation of the carotid sheath, especially in the posterior, misplacement of the clamps or bipolar coagulation ${ }^{(21)}$.

Some specific measures are available in order to avoid vagal nerve injury Careful separation of the vagus nerve from the carotid artery in carotid dissection prevents injury to the vagus nerve during carotid clamping.The dissection also needs to be closer to CCA and IJV. Besides carotid arteries should not be overmanipulated. When applying sharp retractors, care must be given to deep surgical planes (tracheoesophageal grove) to avoid possible vagal nerve nerve and RLN injuries. You have to avoid vagal nerve injury, and be aware of applying clamps on CCA/ICA. Coagulation should be used in appropriate low setting and direct and careful coagulation have to be preferred especially when coagulating anatomical structures close to the CCA and IJV (4,5,21,22).

\section{CONCLUSION}

Our study provides a reliable anatomical knowledge on vagus nerve for CEA. A considerable asymmetry was seen in anatomical relations between vagus nerve, and vascular structures as CCA and IJV.on both sides, During surgery defined considerable asymmetry should be taken into consideration to pre- 
vent possible complications. In our study right side was regarded safer than the left one in terms of vagal nerve injury.

\section{Acknowledgements}

We would like to thank Derya Karataş M.D for drawing the schematic description of anatomical relations between vagus nerve, common carotid artery and internal jugular vein (Figure 1).

Ethics Committee Approval: Ethical Approval was not required for this type of study at our institute (2020/84).

Conflict of Interest: The authors declared that there is no conflict of interest regarding the publication of this article.

\section{Funding: None}

Informed Consent: None (cadaveric study).

\section{REFERENCES}

1. Noiphithak R, Liengudom A. Recent update on carotid endarterectomy versus carotid artery stenting. Cerebrovasc Dis. 2017;43(1-2):68-75.

2. Sajid MS, Vijagnagar B, Singh $P$, Hamilton $G$. Literature review of cranial nerve injuries during carotid endarterectomy. Acta Chir Belg. 2007;107(1):23-8.

3. Wolfe SQ, West JL, Fargen KM, Wilson JA. Complications of carotid endarterectomy. In: Complications in Neurosurgery; 2019. p. 70-6

4. AbuRahma AF, Lim RY. Management of vagus nerve injury afer carotid endarterectomy. Surgery. 1996;119(3):245-7.

5. Fokkema M, de Borst GJ, Nolan BW, et al. Clinical relevance of cranial nerve injury following carotid endarterectomy. Eur J Vasc Endovasc Surg. 2014;47(1):2-7.

6. Park JK, Jeong SY, Lee JH, Lim GC, Chang JW. Variations in the course of the cervical vagus nerve on thyroid ultrasonography. AJNR Am J Neuroradiol. 2011;32(7):1178-81.

7. Tubbs RS, Loukas M, Shoja MM, et al. An unreported variation of the cervical vagus nerve: Anatomical and histological observations. Folia Morphol (Warsz). 2007;66(2):155-7.

8. Planitzer U, Hammer $\mathrm{N}$, Bechmann I, et al. Positional relations of the cervical vagus nerve revisited. Neuromodulation. 2017;20(4):361-8.

9. Sagayaraj A, Deo RP, Merchant S, Mohiyuddin SA, Nayak AC. Medially placed vagus nerve in relation to common carotid artery: A pointer to a non-recurrent laryngeal nerve. Eur Arch Otorhinolaryngol. 2015;272(10):3027-30.

10. Logan BM, Reynolds P, Rice S, Hutchings RT. McMinn's color atlas of head and neck anatomy e-book. Elsevier Health Sciences; 2016

11. Lo A, Oehley M, Bartlett A, Adams D, Blyth P, Al-Ali S. Anatomical variations of the common carotid artery bifurcation. ANZ J Surg. 2006;76(11):970-2.

12. Safar HA, Doobay B, Evans G, Kazemi K, Jahromi A, Cina CS. Retrojugular approach for carotid endarterectomy: A prospective cohort study. J Vasc Surg. 2002;35(4):737-40.

13. Liu Z, Shi Z, Wang Y, et al. Carotid artery stenting versus carotid endarterectomy: Systematic review and meta-analysis. World J Surg. 2009;33:586-96.

14. Brott TG, Calvet D, Howard G, et al. Longterm outcomes of stenting and endarterectomy for symptomatic carotid stenosis: A preplanned pooled analysis of individual patient data. Lancet Neurol. 2019;18(4):348-56.

15. Lepore MR, Sternbergh WC III, Salartash K, Tonnessen B, Money SR. Influence of NASCET/ACAS trial eligibility on outcome after carotid endarterectomy. J Vasc Surg. 2001;34(4):581-6.

16. Hertzer NR. The current status of carotid endarterectomy, part I: Randomized trials versus medical management. Ann Vasc Surg. 2017;43:1-23.

17. Hertzer NR. The current status of carotid endarterectomy part II: randomized trials versus angioplasty and stenting. Ann Vasc Surg. 2017;43:24-40.

18. Giles KA, Hamdan AD, Pomposelli FB, et al. Regarding "Stroke and death after carotid endarterectomy and carotid artery stenting with and without high risk criteria". J Vasc Surg. 2011;54(1):284-5.

19. Lokuge K, de Waard DD, Halliday A, Gray A, Bulbulia R, Mihaylova B. Meta-analysis of procedural risks of carotid endarterectomy and carotid artery stenting over time. $\mathrm{Br} \mathrm{J}$ Surg. 2018;105(1):26-36.

20. Moresoli P, Habib B, Reynier P, Secrest MH, Eisenberg MJ, Filion KB. Carotid stenting versus endarterectomy for asymptomatic carotid artery stenosis: A systematic review and meta-analysis. Stroke. 2017;48(8):2150-7.

21. Schauber MD, Fontenelle LJ, Solomon JW, Hanson TL. Cranial/ cervical nerve dysfunction after carotid endarterectomy. J Vasc Surg. 1997;25(3):481-7.

22. Kakisis JD, Antonopoulos CN, Mantas G, Moulakakis KG, Sfyroeras G, Geroulakos G. Cranial nerve injury after carotid endartercetomy: Incidence, risk factors, and time trends. Eur J Vasc Endovasc Surg. 2017;(53):320-35. 